\title{
CFD Analysis of a Tubular-Type Testing Unit for SOFC
}

\author{
Nobuhide TAKAHASHI ${ }^{1}$, Hidenori KAGAMIFUCHI ${ }^{2}$, \\ Akifusa HAGIWARA ${ }^{2}$ and Koichi YAMADA ${ }^{3}$ \\ ${ }^{1}$ Department of Fine Materials Engineering, Shinshu University, \\ 3-15-1, Tokida, Ueda-shi, Nagano 386-8567, Japan \\ ${ }^{2}$ The Tokyo Electric Power Company, Inc., 4-1, Egasaki, \\ Tsurumi-ku, Yokohama-shi, Kanagawa 230-8510, Japan \\ ${ }^{3}$ The University of Tokyo, 7-3-1 Hongo, Bunkyo-ku, \\ Tokyo 113-8654, Japan
}

\section{Keywords: SOFC Testing Device, CFD Analysis, Cell Performance, Heat and Mass Transfer}

\begin{abstract}
A simulation model has been developed for the analysis of heat, flow and mass transfer coupled with the electrochemical reactions and current collection of a solid oxide fuel cell (SOFC) located in a doubletube type testing device. The simulation model was used to examine the influence of the current collection conditions and gas flow rates on the temperature and concentration fields in the device, and on the resulting cell performance. The results indicated that the high flow rate of air induced a great temperature gradient near the cell surface. It was also pointed out that the low flow rate of fuel significantly lowered the cell performance through the concentration field, especially when the flow channel for fuel gas was not enough long. The mathematical simulation of the phenomena occurring in the testing device as well as at the cell can be a strong measure for precise interpretation of the experimental results and the development of SOFCs.
\end{abstract}

\section{Introduction}

Solid oxide fuel cells (SOFCs) are promising energy conversion devices due to their high efficiency at high operating temperatures ranging from 800 to $1000^{\circ} \mathrm{C}$. However, the development of SOFC requires the examination of numerous parameters. In addition, many of the phenomena dominating the performance of a SOFC are complex and not well understood. Experimental examination of all the parameters is time consuming and expensive. On the other hand, mathematical simulation is helpful in examining numerous parameters, and is expected to expedite the development and understanding of SOFCs. Recently, a computational fluid dynamics (CFD) technique has been more often employed to analyze performances of SOFCs in various configurations (for example, William et al., 2003; Autissier et al., 2004; Li and Suzuki, 2004).

Testing devices of the double-tube type are often employed in examining the performance of a single cell SOFC. However, the influence of heat, flow and concentration fields in the device on the cell performance are often not taken into account, although they have a close relationship with the cell performance.

Received on May 17, 2007; accepted on September 4, 2007. Correspondence concerning this article should be addressed to N. Takahashi (E-mail address: novhide@shinshu-u.ac.jp). Presented at International Symposium on Innovative Materials for Processes in Energy Systems, IMPRES, Kyoto, October, 2007.
For more precise evaluation of the cell performance, phenomena occurring in the testing device need to be understood in detail. Therefore, in this study, a simulation model for heat, flow and mass transfer coupled with models of electrochemical reactions and current collection at a single cell located in the testing device has been developed. The commercial CFD software FLUENT (Fluent Inc.) was used and coupled with inhouse subroutines for the electrochemical reactions and current collection at the cell.

\section{Simulation Method}

\subsection{Configuration of SOFC testing unit}

The configuration of SOFC testing device was reproduced in the simulation model based on the one employed in the experiment. The testing device was assumed to be a double-tube type with a total length of $25 \mathrm{~cm}$, which was installed in an electrical furnace, as shown in Figure 1. A button-type, anode-supported single cell was positioned at the center of the tubes. The flow paths were separated by the cell, and fuel and air were fed into the inner tubes at opposite ends to each other. The supposed fuel was hydrogen with $3 \%$ water vapor. The simulated cell was $35 \mathrm{~mm}$ in diameter and was composed of a LSM/YSZ (lanthanum strontium manganate/yttria-stabilized zirconia) cathode, ScSZ (scandia-stabilized zirconia) electrolyte, and a Ni/YSZ anode. The thicknesses of the cathode, electrolyte and anode layers were 10, 30 and $450 \mu \mathrm{m}$, 
Table 1 Properties of the materials

\begin{tabular}{|c|c|c|c|c|c|}
\hline & $\begin{array}{c}\text { Porosity } \\
{[-]}\end{array}$ & $\begin{array}{l}\text { Density } \\
{\left[\mathrm{kg} / \mathrm{m}^{3}\right]}\end{array}$ & $\begin{array}{c}\text { Conductivity } \\
{[\mathrm{S} / \mathrm{cm}]}\end{array}$ & $\begin{array}{l}\text { Thermal conductivity } \\
{[\mathrm{W} /(\mathrm{m} \mathrm{K})]}\end{array}$ & $\begin{array}{c}\text { Specific heat } \\
{[\mathrm{J} /(\mathrm{kg} \mathrm{K})]}\end{array}$ \\
\hline (Ni/YSZ) & 0.35 & 2000 & 1000 & 6.0 & 620 \\
\hline Cathode (LSM/YSZ) & 0.30 & 2000 & 100 & 4.0 & 430 \\
\hline Electrolyte(ScSZ) & 0 & 4000 & 0.31 & 1.62 & 640 \\
\hline Guide tube $\left(\mathrm{Al}_{2} \mathrm{O}_{3}\right)$ & 0 & 3800 & - & 6.13 & 1200 \\
\hline
\end{tabular}

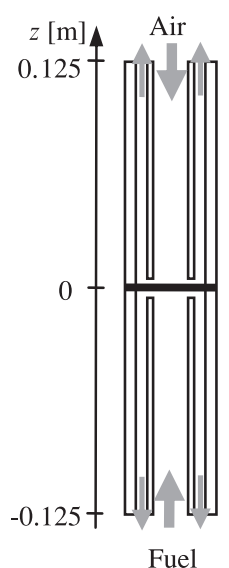

(a) Overall view

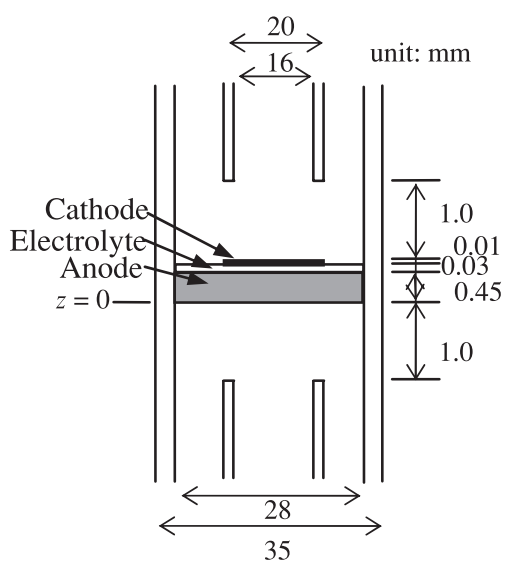

(b) Details of the cell
Fig. 1 Cross-sectional image of the SOFC testing device

respectively. The material used for the gas guide tubes was $\mathrm{Al}_{2} \mathrm{O}_{3}$. The properties of the materials employed in the simulation model are summarized in Table 1. In this study, these properties are assumed to be independent of temperature.

\subsection{Governing equations}

Every equation considers the three dimensions of space and the time dimension although the steady-state condition is supposed in the present study. The gas flows are assumed as compressible and there are no chemical reactions in the gas channels. The four equations for conservation of mass, momentum, energy, and concentration are given as the following.

The conservation of mass

$$
\frac{\partial \rho}{\partial t}+\nabla \cdot(\rho \vec{v})=S_{\mathrm{m}}
$$

where $S_{\mathrm{m}}$ is the additional mass sources.

The conservation of momentum

$$
\frac{\partial}{\partial t}(\rho \vec{v})+\nabla \cdot(\rho \vec{v} \vec{v})=-\nabla p+\nabla \cdot(\overline{\bar{\tau}})+\rho \vec{g}+\vec{F}
$$

where $\overline{\bar{\tau}}=\mu\left[\left(\nabla \vec{v}+\nabla \vec{v}^{\mathrm{T}}\right)-(2 / 3) \nabla \cdot \vec{v} I\right]$ and $I$ is unit tensor. $\vec{F}$ is the external body force. The conservation equation for a chemical species, $i$

$$
\frac{\partial}{\partial t}\left(\rho Y_{i}\right)+\nabla \cdot\left(\rho \vec{v} Y_{i}\right)=-\nabla \cdot \vec{J}_{i}
$$

The diffusion flux in a laminar flow using Fick's law

$$
\vec{J}_{i}=-\rho D_{i, \mathrm{~m}} \nabla Y_{i}
$$

Here, the diffusion flux due to thermal diffusion is neglected. $D_{i, \mathrm{~m}}$ is the diffusion coefficient in the mixture and calculated as

$$
D_{i, \mathrm{~m}}=\frac{1-X_{i}}{\sum_{j, j \neq 1}\left(X_{j} / D_{i j}\right)}
$$

In the present study, heat transfer by radiation is not considered. The conservation of energy

$$
\begin{aligned}
& \frac{\partial}{\partial t}(\rho E)+\nabla \cdot[\vec{v}(\rho E+p)] \\
& =\nabla \cdot\left[k \nabla T-\sum_{j} h_{j} \vec{J}_{j}+(\overline{\bar{\tau}} \cdot \vec{v})\right]+S_{\mathrm{h}}
\end{aligned}
$$

where $S_{\mathrm{h}}$ is the additional energy sources.

In the porous electrodes, the four equations for conservation of mass, momentum, energy, and concentration are replaced with the following, respectively.

$$
\begin{aligned}
& \frac{\partial(\varepsilon \rho)}{\partial t}+\nabla \cdot(\varepsilon \rho \vec{v})=0 \\
& \frac{\partial}{\partial t}(\varepsilon \rho \vec{v})+\nabla \cdot(\varepsilon \rho \vec{v} \vec{v})=-\varepsilon \nabla p+\nabla \cdot(\varepsilon \overline{\bar{\tau}})
\end{aligned}
$$

$$
\begin{aligned}
& \frac{\partial}{\partial t}\left[\varepsilon \rho_{\mathrm{f}} E_{\mathrm{f}}+(1-\varepsilon) \rho_{\mathrm{s}} E_{\mathrm{s}}\right]+\nabla \cdot\left[\vec{v}\left(\rho_{\mathrm{f}} E_{\mathrm{f}}+p\right)\right] \\
& =\nabla \cdot\left[k \nabla T-\sum_{j} h_{j} \vec{J}_{j}+(\overline{\bar{\tau}} \cdot \vec{v})\right]+S_{\mathrm{h}}
\end{aligned}
$$

$$
\frac{\partial\left(\varepsilon \rho Y_{i}\right)}{\partial t}+\nabla \cdot\left(\varepsilon \rho \vec{v} Y_{i}\right)=-\nabla \cdot\left(\varepsilon \vec{J}_{i}\right)+\varepsilon S_{i}
$$




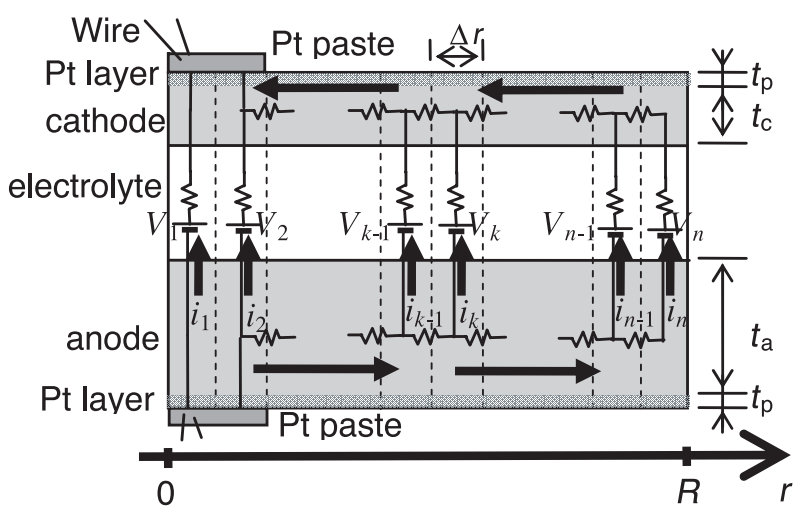

Fig. 2 Equivalent electrical circuit of a single-cell for the proposed current collection model

In the momentum equation in the porous electrodes, the viscous and inertial drag forces are not considered in the present study.

In the guide tubes and the electrolyte layer treated as solid wall, heat transfer only by conduction is considered.

\subsection{Current collection model}

Figure 2 illustrates the equivalent electrical circuit of the cell proposed for the model. Pt paste was placed at the center of both electrode surfaces. Current was assumed to flow only in the vertical direction in the electrolyte layer and only in the horizontal direction toward the center of the cell in the electrodes. Thin Pt layers were also placed over the electrode surfaces to assist current collection. The Pt layers were assumed to not block gas diffusion into and out of the porous electrodes. Finally, the collected current is removed by the Pt wires attached to the Pt paste. The thickness of the Pt layer is $2.0 \mu \mathrm{m}$. The condition for current collection can be adjusted by varying the conductivity of the Pt paste layer, $\sigma_{\mathrm{p}}$. In the present study, $\sigma_{\mathrm{p}}$ was assumed to be $23,000 \mathrm{~S} / \mathrm{cm}$ for a case of poor current collection, and a hundred times larger for a case of good current collection.

The cell was divided into annular volume elements with a width of $\Delta r$. Electrical resistances in the horizontal direction at $r$, between the neighboring volume elements of the anode and cathode, can be expressed by the following equations:

$$
\begin{array}{ll}
\text { Cathode: } & g_{\mathrm{c}}(r)=\frac{\Delta r}{2 \pi r\left(\sigma_{\mathrm{c}} t_{\mathrm{c}}+\sigma_{\mathrm{p}} t_{\mathrm{p}}\right)} \\
\text { Anode: } & g_{\mathrm{a}}(r)=\frac{\Delta r}{2 \pi r\left(\sigma_{\mathrm{a}} t_{\mathrm{a}}+\sigma_{\mathrm{p}} t_{\mathrm{p}}\right)}
\end{array}
$$

The electrical resistance of the volume element across the electrolyte is calculated by the following equation:
Electrolyte: $f(r)=\frac{R_{\text {cell }}}{2 \pi r \Delta r}$

Here, $R_{\text {cell }}$ is the total resistance $\left[\Omega \cdot \mathrm{m}^{2}\right]$ measured experimentally and includes the bulk resistance of the cell and the polarization resistances at both electrodes.

In the calculation, the total current is externally specified and the Nernst voltage is calculated at each radial position based on the gas compositions in the electrodes. Consistent distribution of the current density is calculated using the total current, the resistances and the distribution of the Nernst voltage.

\subsection{Nernst potential}

The reactions at both electrodes and the overall reaction are expressed as follows:

$$
\begin{aligned}
& \text { Cathode: } \frac{1}{2} \mathrm{O}_{2}+2 \mathrm{e}^{-}=\mathrm{O}^{2-} \\
& \text { Anode: } \mathrm{H}_{2}+\mathrm{O}^{2-}=\mathrm{H}_{2} \mathrm{O}+2 \mathrm{e}^{-} \\
& \text {Overall: } \mathrm{H}_{2}+\frac{1}{2} \mathrm{O}_{2}=\mathrm{H}_{2} \mathrm{O}
\end{aligned}
$$

The Nernst voltage, $V_{\text {oc }}$ [V], can be calculated by the following equation at each radial position, using the distribution at each radial position from the partial pressures of gas components in both electrodes immediately above the electrolyte surfaces at that position.

$$
V_{\mathrm{OC}}=\frac{-\Delta G^{0}}{2 F}+\frac{R T}{2 F} \ln \frac{p_{\mathrm{H}_{2}, \text { anode }} p_{\mathrm{O}_{2}, \text { cathode }}}{p_{\mathrm{H}_{2} \mathrm{O}, \text { anode }}}
$$

\subsection{Chemical reaction and heat generation rates}

The generation rate $S_{i}\left[\mathrm{~kg} /\left(\mathrm{m}^{3} \cdot \mathrm{s}\right)\right]$ of a gas species $i$ is given by the following equation:

$$
S_{i}=-\frac{M_{i} v_{i} i}{2 F t}
$$

Here, $t$ represents the thickness of the layer where the chemical reaction occurs. For the simulation model, it was assumed that the reactions occurred uniformly along the vertical direction in the layer. The thickness of the reaction region was $10 \mu \mathrm{m}$ for the cathode because the cathode was sufficiently thin. For the anode, some researchers have reported effective thicknesses ranging from $10 \mu \mathrm{m}$ to over than $100 \mu \mathrm{m}$ (Fukunaga et $a l ., 2007)$. In this study, the thickness of the reaction region was assumed to be $50 \mu \mathrm{m}$ for the anode.

Furthermore, the heat generation rate $S_{\mathrm{h}}\left[\mathrm{W} / \mathrm{m}^{3}\right]$ was assumed to be uniform along the vertical direction in the electrolyte layer and is calculated by the following equation: 


$$
S_{\mathrm{h}}=\frac{i}{2 F t_{\mathrm{e}}} T \Delta S^{0}+\frac{i^{2} R_{\text {cell }}}{t_{\mathrm{e}}}
$$

Here, the first term on the right-hand represents the heat generated by the entropy change of the overall reaction, and the second term represents Joule heat due to the bulk and polarization resistances. $t_{\mathrm{e}}$ represents the thickness of the electrolyte layer.

\subsection{Grid system}

A grid system of the model of testing unit was created by using GAMBIT, another software building and meshing a model. In the present study, the thickness of the electrodes and electrolyte is less than $1 \mathrm{~mm}$ while the length of the flow channel on each side is $125 \mathrm{~mm}$. Therefore, mesh size must be changed with the calculated zones both for sufficiently high resolution around the cell and reduction of the calculation cost.

The electrolyte and cathode layers were equally divided in the $z$-direction and the mesh size of them was $6 \mu \mathrm{m}$ and $2.5 \mu \mathrm{m}$, respectively. The anode layer was divided into ten in the $z$-direction and the mesh size geometrically increased from 10 to $114 \mu \mathrm{m}$ with increasing the distance from the interface between the anode and the electrolyte. On the other hand, the mesh size in the $z$-direction for the flow channels also geometrically increased with increasing the distance from the cell, from $10 \mu \mathrm{m}$ to $9.36 \mathrm{~mm}$ on the cathode side and from $200 \mu \mathrm{m}$ to $9.36 \mathrm{~mm}$ on the anode side.

For the grid system on the cross-section of the model, the part except the circular area of $1 \mathrm{~mm}$ in radius at the center was equally divided into 32 in the circumferential direction and 33 with a width of $0.5 \mathrm{~mm}$ in the radial direction. For the center area, meshes with sufficiently small sizes were created by the meshing scheme with "Quad" as element and "Pave" as type.

\subsection{Discretization}

The governing equations must be converted to algebraic equations that can be solved numerically. The diffusion terms in these equations were centraldifferenced using values at the centers of the control volumes. For the convection terms, values at the interface between neighboring control volumes are required and must be interpolated from the center values. In the present study, first-order upwind scheme was employed, where the face value was set equal to the center value in the upstream control volume.

\subsection{Boundary conditions and calculation methods}

"Mass flow inlet boundary conditions" were selected for the inlets of the air and fuel flow channels. The flow rate at the fuel inlet was varied from 100 to $1000 \mathrm{~cm}^{3} / \mathrm{min}$, and the flow rate at the air inlet was varied between 250 and $1500 \mathrm{~cm}^{3} / \mathrm{min}$ at $298.15 \mathrm{~K}$ and $1.0 \mathrm{~atm}$. These flow rates were converted to the mass flow rates in $\mathrm{kg} / \mathrm{s}$ for the selected boundary condition

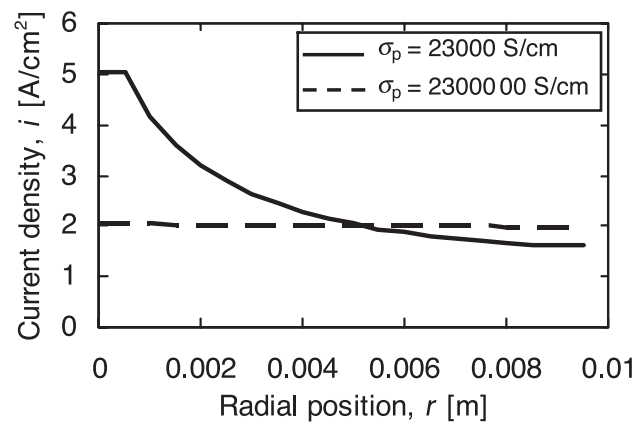

Fig. 3 Current density distributions for low and high $\sigma_{\mathrm{p}}$ (air flow rate, $1500 \mathrm{~cm}^{3} / \mathrm{min}$; fuel flow rate, 500 $\mathrm{cm}^{3} / \mathrm{min}$ )

type. The temperatures of the fuel and air at the inlets were $470-505 \mathrm{~K}$. The Reynolds number calculated under these conditions indicated that the flows were laminar in the air and fuel flow channels. At the outlets of both flow channels, "Pressure outlet boundary conditions" was selected and the gauge pressure was set to zero.

"External radiation boundary condition" was selected for the temperature boundary condition on the outer surface of the outer guide tube. The emissivity of the virtual radiation wall was set to one, and the radiation temperature was adjusted such that the temperature at the center of the cathode surface was maintained within a range of $1273 \pm 0.5 \mathrm{~K}$.

Heat and mass transfer were calculated using the software FLUENT, and the distributions of current density and potential were calculated by the in-house subroutines coupled with FLUENT. These were calculated iteratively until a steady-state was reached.

\section{Results and Discussion}

\subsection{I-V curves at different conditions for current collection}

Figure 3 shows the current density distribution along the radial direction, calculated using different values of $\sigma_{\mathrm{p}}$. In the case of low $\sigma_{\mathrm{p}}$, the current density significantly varied along the radial direction. The value at the center was approximately three times as large as that at the edge of the cell. On the other hand, for the case of high $\sigma_{\mathrm{p}}$, the current density distribution was almost flat.

I-V curves calculated under these two $\sigma_{\mathrm{p}}$ conditions are shown in Figure 4. The I-V curve for high $\sigma_{\mathrm{p}}$ corresponded well with the measured curve (not shown here), indicating good current collection for the experiment single cell. The I-V curve for low $\sigma_{\mathrm{p}}$ shows a significant drop in the terminal voltage due to a large current collection loss.

Figure 5 shows the temperature distribution of the cathode surface along the radial direction for the two 


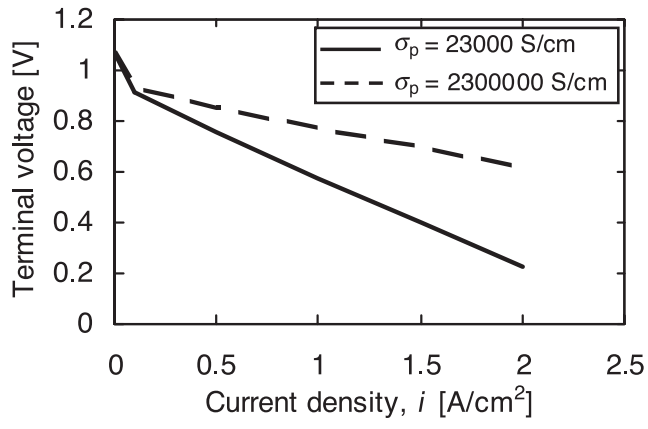

Fig. 4 I-V curves for low and high $\sigma_{\mathrm{p}}$ (air flow rate, 1500 $\mathrm{cm}^{3} / \mathrm{min}$; fuel flow rate, $500 \mathrm{~cm}^{3} / \mathrm{min}$ )

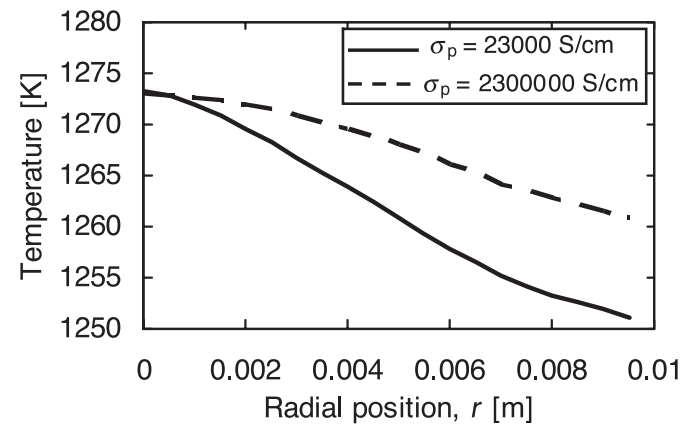

Fig. 5 Temperature distributions of the cathode surface for low and high $\sigma_{\mathrm{p}}$ (air flow rate, $1500 \mathrm{~cm}^{3} / \mathrm{min}$; fuel flow rate, $500 \mathrm{~cm}^{3} / \mathrm{min}$; average current density, $2.0 \mathrm{~A} / \mathrm{cm}^{2}$ )

current collection cases. In both cases, the temperature was highest at the center and decreased with increasing distance from the center. The temperature difference between the center and the edge of the cell was $22 \mathrm{~K}$ and $12 \mathrm{~K}$ for low and high $\sigma_{\mathrm{p}}$, respectively. The larger temperature difference in the case of low $\sigma_{\mathrm{p}}$ can be explained by the current density distribution shown in Figure 3. It is surprising that the temperature difference varied by $12 \mathrm{~K}$ between the center and the edge even in the case of high $\sigma_{\mathrm{p}}$, although the current density was uniform over the cell surface. It should be noted that the temperature monitored in the experiment significantly varies with position.

\subsection{Effects of gas flow rate on the temperature field}

Changes in the temperature distribution along the central axis of the guide tubes with the change in the boundary conditions of the air and fuel flow rates are shown in Figures 6 and 7, respectively. As seen in Figure 6 , the air could not be fully heated before it reached the cell when the air flow rate was high, because the thermal conductivity of the gas mixture is low. The temperature gradient near the cathode surface increased with an increase in the air flow rate, ranging from 16 $\mathrm{K} / \mathrm{mm}$ at a flow rate of $250 \mathrm{~cm}^{3} / \mathrm{min}$ to $83 \mathrm{~K} / \mathrm{mm}$ at a flow rate of $1500 \mathrm{~cm}^{3} / \mathrm{min}$. On the other hand, the fuel

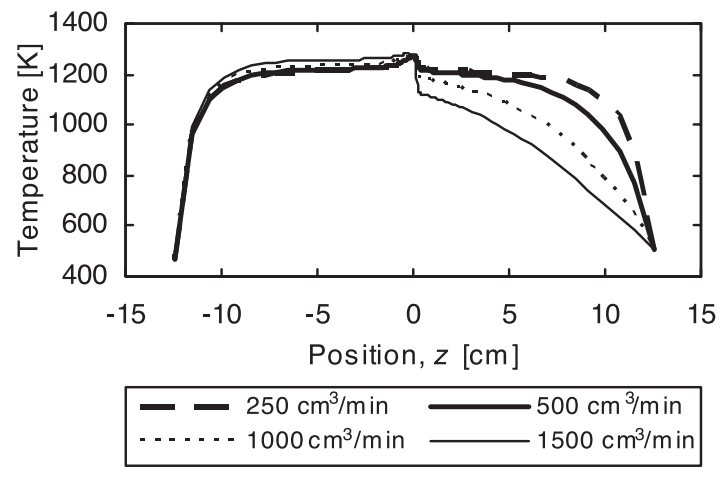

Fig. 6 Change in the temperature distribution along the central axis with change in the air flow rate (fuel flow rate, $500 \mathrm{~cm}^{3} / \mathrm{min}$; average current density, 2.0 $\left.\mathrm{A} / \mathrm{cm}^{2} ; \sigma_{\mathrm{p}}, 2,300,000 \mathrm{~S} / \mathrm{cm}\right)$

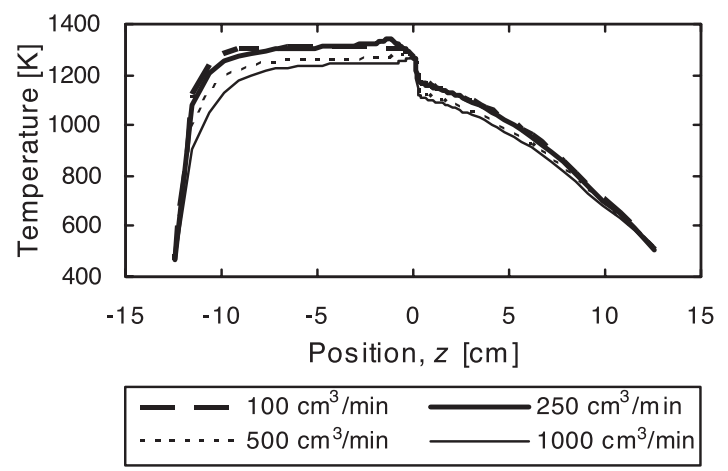

Fig. 7 Change in the temperature distribution along the central axis with the change in the fuel flow rate (air flow rate, $1500 \mathrm{~cm}^{3} / \mathrm{min}$; average current density, $\left.2.0 \mathrm{~A} / \mathrm{cm}^{2} ; \sigma_{\mathrm{p}}, 2,300,000 \mathrm{~S} / \mathrm{cm}\right)$

was fully heated before reaching the cell even when the fuel flow rate increased up to $1000 \mathrm{~cm}^{3} / \mathrm{min}$, and the temperature gradient near the cell surface was reasonably small.

The cell temperature is often measured with thermocouples on the cathode surface when testing a single cell SOFC. These results indicate that the cell temperature should be carefully measured to avoid measurement errors, especially at a high air flow rate.

\subsection{Effects of gas flow rate on the species concen- tration field}

The left-hand side of Figure 8 shows the change in the $\mathrm{H}_{2}$ mole fraction distribution along the centerline of the tubes with the change in the fuel flow rate. The change in the $\mathrm{O}_{2}$ mole fraction distribution with the change in the air flow rate is shown on the right-hand side of Figure 8. It can be seen that the air flow rate has a small influence on the concentration field, although the concentration boundary layer slightly extends into the upstream with decreasing air flow rate. The length of the guide tubes used in the model was 


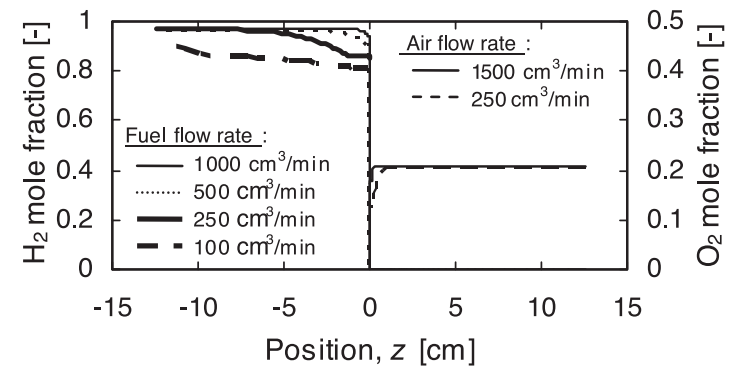

Fig. 8 Change in composition distribution along the central axis with the change in the gas flow rate (left, $\mathrm{H}_{2}$ mole fraction distribution change with change in the fuel flow rate; right, $\mathrm{O}_{2}$ mole fraction distribution change with the change in the air flow rate; average current density, $2.0 \mathrm{~A} / \mathrm{cm}^{2} ; \sigma_{\mathrm{p}}, 2,300,000$ $\mathrm{S} / \mathrm{cm})$

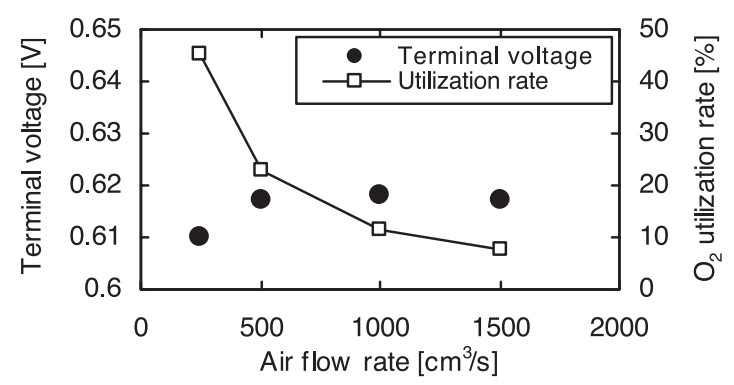

Fig. 9 Changes in the terminal voltage and $\mathrm{O}_{2}$ utilization rate with the change in the air flow rate (fuel flow rate, $500 \mathrm{~cm}^{3} / \mathrm{min}$; average current density, $2.0 \mathrm{~A} /$ $\left.\mathrm{cm}^{2} ; \sigma_{\mathrm{p}}, 2,300,000 \mathrm{~S} / \mathrm{cm}\right)$

found to be sufficiently long with respect to the concentration field.

In contrast, the fuel flow rate had a significant influence on the anode side concentration distribution. The concentration boundary layer was significantly enlarged with a decrease in the fuel flow rate. When the fuel flow rate was decreased to $100 \mathrm{~cm}^{3} / \mathrm{min}$, the reduction in concentration extended to the gas inlet. The utilization rate of $\mathrm{H}_{2}$ at this flow rate and an average current density of $2.0 \mathrm{~A} / \mathrm{cm}^{2}$ was approximately $50 \%$. If the cell performance is evaluated at such a high utilization rate of $\mathrm{H}_{2}$, the length of the guide tube on the anode side should be longer. Thus, the geometry and dimensions of the testing device should be determined with consideration for the phenomena occurring under the supposed conditions.

\subsection{Effects of gas flow rate on cell performance}

Changes in the terminal voltage with respect to changes in the air and fuel flow rates are shown in Figures 9 and 10, respectively. The terminal voltage was calculated at an average current density of $2.0 \mathrm{~A} / \mathrm{cm}^{2}$. The $\mathrm{O}_{2}$ and $\mathrm{H}_{2}$ utilization rates are also shown in the figures.
Table 2 Comparison between the experiment and calculation (Cell temperature, $1273 \mathrm{~K}$; average current density, $2.0 \mathrm{~A} / \mathrm{cm}^{2} ; \sigma_{\mathrm{p}}, 2,300,000$ $\mathrm{S} / \mathrm{cm})$

\begin{tabular}{llll}
\hline Fuel flow rate $\left[\mathrm{cm}^{3} / \mathrm{min}\right]$ & 500 & 500 & 500 \\
Air flow rate $\left[\mathrm{cm}^{3} / \mathrm{min}\right]$ & 1500 & 1000 & 500 \\
Terminal voltage & & & \\
$\quad$ Experiment [V] & 0.65 & 0.65 & 0.65 \\
$\quad$ Calculation [V] & 0.62 & 0.62 & 0.62 \\
& & & \\
Temperature on outer surface & & & \\
$\quad$ Experiment $[\mathrm{K}]$ & 1257 & 1252 & 1249 \\
$\quad$ Calculation $[\mathrm{K}]$ & 1257 & 1232 & 1220 \\
\hline
\end{tabular}

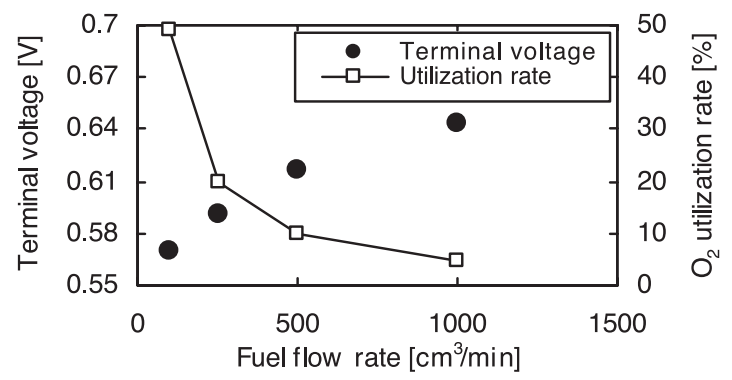

Fig. 10 Changes in the terminal voltage and $\mathrm{H}_{2}$ utilization rate with the change in the fuel flow rate (air flow rate, $1500 \mathrm{~cm}^{3} / \mathrm{min}$; average current density, 2.0 $\mathrm{A} / \mathrm{cm}^{2} ; \sigma_{\mathrm{p}}, 2,300,000 \mathrm{~S} / \mathrm{cm}$ )

The terminal voltage was decreased by less than $0.01 \mathrm{~V}$ with a decrease in the air flow rate from 1500 to $250 \mathrm{~cm}^{3} / \mathrm{min}$, although the $\mathrm{O}_{2}$ utilization rate was largely increased from 7.6 to $45 \%$ with the same change in the air flow rate. On the other hand, the terminal voltage was decreased by $0.074 \mathrm{~V}$ when the fuel flow rate was decreased from 1000 to $100 \mathrm{~cm}^{3} / \mathrm{min}$, and the $\mathrm{H}_{2}$ utilization rate was increased from 4.9 to $49 \%$. The fuel flow rate had more significant influence on the cell performance.

It is desirable that a SOFC system should be operated at a high utilization rate of $\mathrm{H}_{2}$ for safety reasons as well as efficient utilization of the fuel. However, as discussed in this and the previous sections, the fuel flow rate has a significant influence on the concentration field, not only near the cell but in the flow channel, and on the resulting cell performance, especially at high current density. In such a case, the experimental conditions and the geometry of the device have to be determined carefully.

\subsection{Verification of the simulation model}

Table 2 shows the comparison between the results obtained from the calculation and the experiment which was performed using the testing unit having the same configuration as that in the simulation model except the guide tubes were longer than those in the model. 
Temperature was measured on the outer surface of the outer guide tube at $z=0.01 \mathrm{~m}$ using a thermocouple in the experiment. The calculated value of terminal voltage corresponded well with the measured values under the given flow rate conditions. The calculated value of the temperature on the outer surface was in good agreement with the measured value when the air flow rate was $1500 \mathrm{~cm}^{3} / \mathrm{min}$ and the fuel flow rate was 500 $\mathrm{cm}^{3} / \mathrm{min}$. As the air flow rate decreased, however, the calculated temperature decreased more quickly than the measured one. The reason is not clear at the present stage. One possible reason may be associated with heat transfer by radiation, which was not treated in the present simulation model. If the radiation heat transfer is taken into account, the temperature distribution in the system may become flatter and the influences of the conditions such as flow rates on the temperature field is expected to be reduced. In the future model, the radiation heat transfer should be incorporated.

\section{Conclusions}

A simulation model was used to examine the influence of the current collection conditions and the gas flow rates on the temperature and concentration fields in a double-tube type testing device for a single-cell SOFC, and on the resulting cell performance.

Even with good current collection, the temperature largely varied with positions on the cell, indicating that the cell temperature measured in the experiment includes some error due to the temperature distribution. The air could not be fully heated before it reached the cell, resulting in a large temperature gradient near the cell at a high air flow rate. This suggests that the cell temperature should be carefully measured on the cathode surface. The fuel flow rate had a great influence on the concentration field in the flow channel as well as near the cell, and consequently, on the cell performance. If a single cell is tested at a high utilization rate of fuel, it is necessary that the length of the fuel feed flow channel be sufficiently long.

Thus, the mathematical simulation clarified the effects of the experimental conditions on the temperature and concentration distributions in the testing device as well as at the cell, which are closely related to the cell performance but hard to be measured experimentally. Such approach to interpret experimental results for the SOFC systems is useful to design and establish efficient SOFC systems.

Nomenclature
$\begin{array}{lll}D_{i j} & = & \text { binary mass diffusion coefficient } \\ D_{i, \mathrm{~m}} & = & \text { diffusion coefficient for species in the mixture }\end{array}$

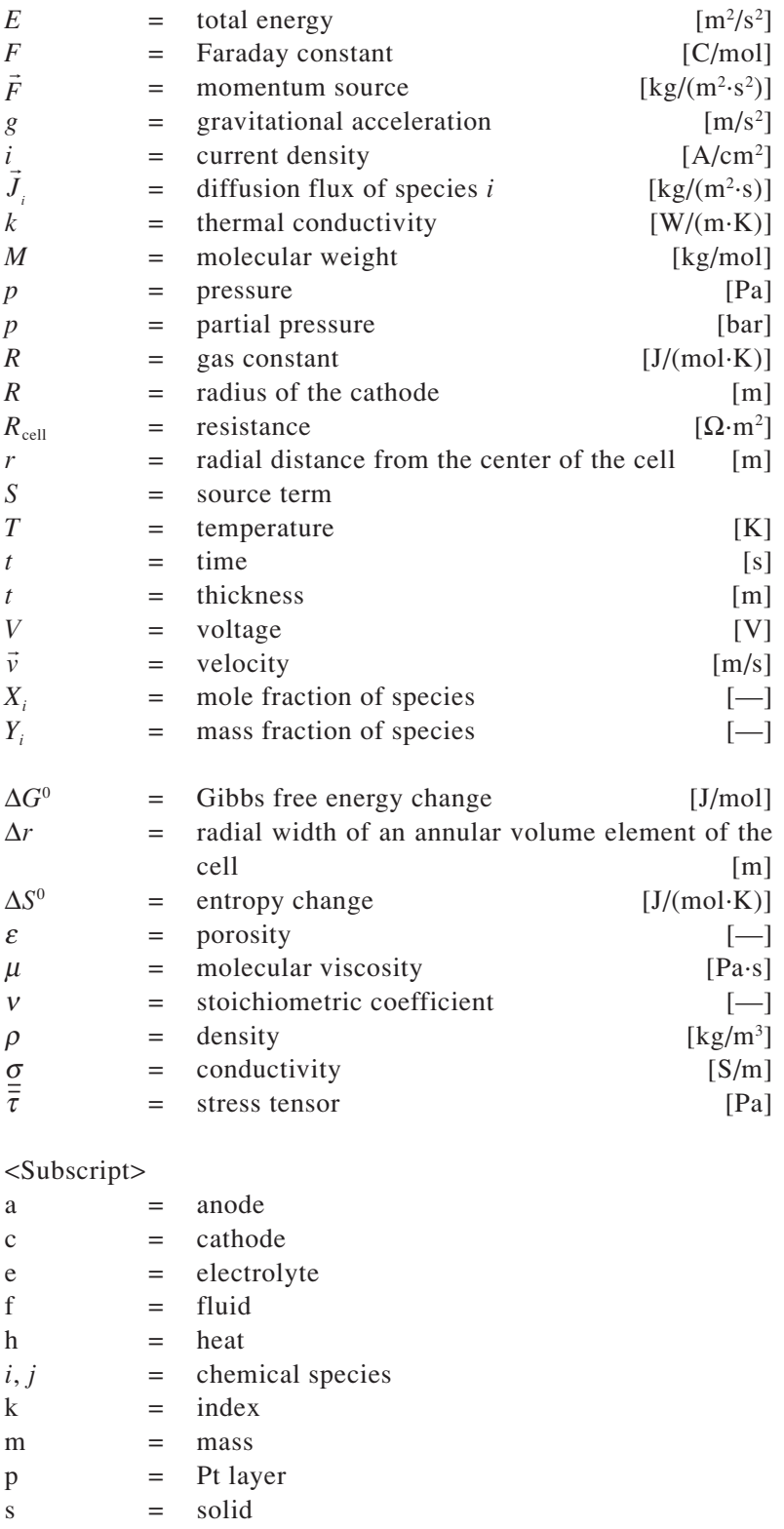

Gibbs free energy change

[J/mol] radial width of an annular volume element of the cell

$[\mathrm{m}]$

entropy change $\quad[\mathrm{J} /(\mathrm{mol} \cdot \mathrm{K})]$

porosity

molecular viscosity

stoichiometric coefficient

density

conductivity

stress tensor

$<$ Subscript $>$

\section{Literature Cited}

Autissier, N., D. Larrain, J. Van Herle and D. Favrat; "CFD Simulation Tool for Solid Oxide Fuel Cells," J. Power Sources, 131, 313-319 (2004)

Fukunaga, H., M. Ishino and K. Yamada; "Effective Thickness of Ni-Sm-Doped Ceria Cermet Anode for Solid Oxide Fuel Cell," Electrochem. Solid-State Lett., 10, B16-B18 (2007)

Li, P.-W. and K. Suzuki; "Numerical Modeling and Performance Study of a Tubular SOFC," J. Electrochem. Soc., 151, A548A557 (2004)

William, R. A., R. S. Gemmen, C. Johnson, M. Prinkey and M. Shahnam; "Validation and Application of a CFD-Based Model for Solid Oxide Fuel Cells and Stacks," Proc. of the 1st International Conference on Fuel Cell Science, Engineering and Technology, pp. 517-520, New York, U.S.A. (2003) 